\title{
Zeytin Karasuyu Sorununa Yönelik Milas Yöresi Zeytin Üreticileri Görüşlerinin Değerlendirilmesi
}

\section{Evaluation of Olive Famer's Views of the Milas Region on the Olive Mill Wastewater Problems}

\section{Perihan MANAVOĞLU' \\ Murat GÜNER $\dot{I}^{*}$ \\ İbrahim YOKAŞ ${ }^{3}$}

${ }^{1}$ Muğla Sitkı Koçman Üniversitesi, Fen Bilimleri Enstitüsü, Muğla

iD 0000-0002-7039-4725

${ }^{2}$ Muğla Sıtkı Koçman Üniversitesi, Ortaca Meslek Yüksekokulu, Muğla

iD 0000-0002-2086-8953

${ }^{3}$ Muğla Sitk1 Koçman Üniversitesi, Ortaca Meslek

Yüksekokulu, Muğla

iD 0000-0003-2501-7282

\section{*Sorumlu yazar:}

gmurat@mu.edu.tr

Bu çalışma, ilk yazarın Muğla Sıtkı Koçman Üniversitesi Fen Bilimleri Enstitüsü Yüksek Lisans Tezi sonuçlarının bir kısmını içermektedir.

Gönderilme Tarihi: Kabul Tarihi
12 Ocak 2021

14 Mart 2021

\section{ÖZET}

Zeytinyağı üretimi sürecinde oluşan atıklar ve özellikle zeytin karasuyu, önemli çevre sorunları arasında yer almaktadır. Bu atıkların bertaraf edilmesi konusunda son yıllarda çok sayıda çalışma yapılmıştır. Karasuyun; organik maddesinin tarımda kullanıldığı, çevreye hiçbir zararı olmayan, ekonomik, ticari gübre kullanımını azaltıcı etkisinin olabileceği çevreci yaklaşımlar geliştirilmiştir.

Bu çalışmada, zeytin üreticilerinin çevresel duyarlılıkları ile karasuyun çevresel etkileri ve bertaraf edilmesi konusunda üreticilerin görüş ve farkındalıklarının belirlenmesi amaçlanmıştır. Bu kapsamda, Milas İlçesi'nde zeytin yetiştiricilerine yönelik anket çalışması yapılmış ve sonuçları değerlendirilmiştir.

Çalışma sonucunda, üreticilerin önemli bir kısmının çevre bilincine sahip olduğu (3.31) belirlenmiştir. Ayrıca, karasuyun çevresel etkileri konusunda orta düzeyde (2.47) farkındalığa sahip oldukları tespit edilmiştir. Bununla birlikte, bertaraf edilmesi konusunda yeterli bilgiye sahip olmadıkları (2.10) belirlenmiştir. Karasuyun kompostlanması ve toprağa uygulanması fikri üreticiler tarafından genel olarak olumlu karşılanmıştır. Bu nedenle üreticiler, karasu sorunun çözümüne katkı sağlayabilecek paydaşlar olarak düşünülmektedir.

Anahtar Kelimeler: Çevre, Karasu, Milas, Üretici, Zeytin, Zeytinyağ 1 


\section{ABSTRACT}

The waste of olive oil especially Olive Mill Wastewater (OMWW) which comes out at the process of olive oil production produces important environmental problems. In recent years, a lot of researches about disposal of this wastes have done. Environmentalist approaches have been developed which comes up with the idea that all the organic matter of OMWW is used in agriculture, having no harm to environment, reducing the usage of commercial fertilizer.

In this study, it was aimed to investigate the environmental consciousness of olive farmers and their views and awareness about the environmental effects and disposal of the OMWW. In this context, a questionnaire was conducted for olive growers in Milas is applied and the results of the questionnaires are evaluated.

According to the results of the study, important part of the growers has the environmental awareness (3.31). In addition, it was determined that farmers are at medium level (2.47) awareness of environmental impacts of OMWW. However, it has been determined that they don't have adequate (2.10) knowledge on the disposal of OMWW. The idea of composting OMWW and applying it to the soil was generally welcomed by the farmers. Therefore, farmers are considered as stakeholders on contributing for the solution of the OMWW problems.

Keywords: Environment, Growers, Milas, Olive, Olive Mill Wastewater, Olive Oil

\section{GİRIS}

Zeytinyağı üretimi sırasında bazı yan ürünler açığa çıkmaktadır. Bunların başında prina ve karasu gelmektedir. Zeytinyağı üretimi sonucu oluşan zeytin karasuyu; zeytinin özsuyu, zeytin yıkama suları, proses sırasında eklenen su ve pirinadan sızan sudan oluşmaktadır (Ben Sassi vd., 2006). Zeytinyağı üretim sistemi, ortaya çıkan karasu miktarı üzerine etkili olmaktadır. Zira, zeytinyağı üretimi sırasında 4.000 ton zeytin işlendiğinde iki fazlı üretim sisteminde $1.200 \mathrm{~m}^{3}$ atık su açığa çıkarken, bu miktar, üç fazlı üretim sisteminde $4.776 \mathrm{~m}^{33} \mathrm{e}$ çıkabilmektedir (Murat Hocaoglu vd., 2018).

Karasuyun yüksek düzeyde organik kirliliğe neden olduğu belirtilmektedir (Tunalığlu ve Bektaş, 2010; Karademir,
2016). Aynı zamanda çeşitli fitotoksit uçucu asitler içermesi ve fenolik bileşikler bulundurması nedeniyle çok toksik bir etkiye sahiptir (Tunç ve Ünlü, 2015). Çok sayıda çalışmada karasu uygulaması ile toprakta tuzluluk ve toksiditede artış, fakat pH'da düşüş olduğu ifade edilmektedir (Moraetis vd., 2011; Di Bene vd., 2013). Yine de, kış mevsimindeki yağışlar, toprakta biriken tuz ve fenolik bileşiklerin yıkanmasına yardımcı olmaktadır (Kapellakis vd., 2015).

Karasu değişik yöntemler ile bertaraf edilmektedir. En yaygın uygulama, açık lagünlerde veya alanlarda buharlaştırmadır (Azbar vd., 2004). Karasuyun bertarafı belirli bir maliyet gerektirmektedir. Maliyet açısından bertaraf alternatiflerinin karşılaştırıldığı bir çalışmada, zeytinyağı işletmeleri açısından en ekonomik çözümün üç fazlı üretimden iki fazlı üretime geçiş (proses değişikliği) olduğu, arazi bedeli ödenmediği takdirde lagünlerin iyileştirilmesinin de uygun olduğu belirtilmektedir (Murat Hocaoğlu vd., 2019). Karasuyun bertarafı konusunda çözüm önerilerinden biri de tarımda kullanılmasıdır. Zira, zeytin karasuyunun toprak verimliliğine olumlu yönde katkı sağladığı (Chaari vd., 2015, Uzun ve Seferoğlu, 2017), korunganın tohum çimlenmesinde, çimlenme oranı ve süresini artırdığı (Altındal ve Altındal 2018) belirtilmektedir. Bunun yanında toprakta mikrobiyal aktiviteyi teşvik ettiği ifade edilmektedir (Buchmann vd., 2015; Okur vd., 2019).

Karasuyun tarımsal faaliyetlerde kullanımına yönelik çok sayıda farklı uygulama yöntemleri denenmiştir. Karasuyun toprağa direkt uygulanması (Saadi vd., 2007; Chaari vd., 2015), kompost materyaline belli oranda karıştırılıp kompostlanması ve toprağa uygulanması (Dakhli vd., 2018; İlay vd., 2019), pirinanın kompostlanması ve toprağa uygulanması (Killi, 2008) bu yöntemlerden bazılarıdır. Zeytinyağı atıklarının ya tek başına (Principi vd., 2003) veya katkı maddeleri ile birlikte karışım halinde kompostlanabileceği bildirilmektedir (Paredes vd., 2002; Garcia-Gomezvd.,2003). Kompostlamaile en az 18 haftanın sonunda zeytinyağı atıkları içindeki fitotoksik maddelerin ortadan kaldırılabileceği ifade edilmektedir (GomezMunoz vd., 2019). Kompostlaştırma çalışmalarında farklı atıklar kullanılmıştır. Bunlar; yün atıkları ve buğday samanı (Altieri ve Esposito, 2010); zeytin yaprakları, odun talaşı ve pirinç yan ürünleri (Komilis ve Tziouvaras, 2009); susam 
kabuğu (Sellami vd., 2008), kanatlı gübresi (Hachicha vd., 2009), koyun gübresi ve üzüm sapları (Cayuela vd., 2010), zeytin yaprakları (Manios vd.,2006; Alfano vd., 2008) ve atık su çamuru (Sánchez-Arias vd., 2008) gibi atıklardır.

$\mathrm{Bu}$ çalışmada; zeytin karasuyunun çevresel sorunları bağlamında, zeytin üreticilerinin çevresel duyarlılıkları ile karasuyun çevresel etkileri ve bertarafı konusunda üreticilerin görüş ve farkındalıklarının belirlenmesi amaçlanmıştır. Çalışmada örnek yöre olarak Milas ilçesi seçilmiştir. Böylece, bir atık olan zeytin karasuyunun tarımda kullanılma olanaklarına üretici yaklaşımı irdelenmeye çalışılmıştır.

\section{MATERYAL ve YÖNTEM}

Araştırmanın ana materyalini, Milas İlçesi'nde zeytin üretiminin yoğun olarak yapıldığı yörelerde zeytin üreticileriyle yapılan anket çalışmaları oluşturmaktadır. Ayrıca konuyla ilgili Milas İlçe Tarım ve Orman Müdürlüğü, Milas Ticaret Odası, Türkiye İstatistik Kurumu (TÜİK) kayıtları; internet üzerinden çeşitli kaynaklar, kitap, makale, tez ve bildirilerden elde edilen verilerden yararlanılmıştır.

Zeytinyağ1 işletmeleri zeytin üretim bölgelerinde bulunduğundan karasuyun kaynağı da bu bölgelerdir. $\mathrm{Bu}$ nedenle karasuyun kaynağa en yakın mesafede olan zeytin üreticileri tarafından, başta zeytin bahçeleri olmak üzere tarım alanlarında kullanılabileceği ve üreticilerin bu konudaki bakış açılarının belirlenmesi gerektiği düşünülmüş ve konuyla ilgili Muğla-Milas yöresinde 2019 yılında üreticilere yönelik anket çalışması yapılmıştır.
Yörede bulunan zeytin işletmeleri hakkında öncelikle bir ön çalışma yapılmış, Ziraat Odası kayıtlarına göre, yöreyi en iyi temsil ettiği düşünülen $11 \mathrm{köy} / \mathrm{mahalle,} \mathrm{gayeli}$ olarak seçilmiştir (Çizelge 1). Bu yerleşim yerlerinde zeytin yetiştiriciliği yapan tüm tarım işletmeleri araştırmanın ana kitlesini oluşturmuş ve örnek büyüklüğünün hesaplanmasında Basit Tesadüfi Örnekleme Yöntemi kullanılmıştır. Buna göre 115 üretici belirlenmiştir. Mahalle ve köylerde tarım işletmesine tesadüfi olarak gidilmiş ve üreticilerle yüz yüze görüşülmüştür. Çalışmada 5'li likert tipi sorular (1: Hiç katılmıyorum, 2: Az katılıyorum, 3: Orta düzey katılıyorum, 4: Oldukça katılıyorum, 5: Çok fazla katılıyorum) kullanılmıştır. Üreticilere sosyoekonomik özellikler, çevresel duyarlılık, karasuyun çevresel etkileri ve bertarafına yönelik görüş ve farkındalıklarının belirlenmesi için sorular yöneltilmiştir.

Anket çalışması, literatür bilgileri ışığında hazırlanan sorulardan oluşturulmuştur. Üreticilerin çevresel duyarlılıklarının belirlenmesinde yeni çevresel paradigma ölçeği (Bektaş ve Şirin, 2018) dikkate alınmıştır. Ayrıca zeytin karasuyuna bakış açıları, bertarafı ve tarımda kullanılabilirliği konusunda farkındalık durumları belirlenmiştir. Elde edilen verilerde, betimsel analizlerde frekans ve oran (\%) teknikleri kullanılmıştır. Sonuçlar analiz edilerek önerilerde bulunulmuştur.

\section{BULGULAR ve TARTIŞMA}

Türkiye'de 2015-2019 dönemi 5 ylllık ortalama yağlık zeytin (zeytinyağ 1 üretimi için) üretim miktarı 1.284.694 ton olup bunun 141.199 tonu Muğla ilinde, 62.185 tonu Milas ilçesinde gerçekleşmiştir (TÜİK, 2019). Üretilen

Çizelge 1. Anket çalışmasının yapıldığı üretim merkezleri ve bölgede mevcut toplam üretici sayısı

\begin{tabular}{|l|l|}
\hline Mahalle /köy sayısı & \\
\hline Toplam zeytin üreticisi sayısı & $\begin{array}{l}\text { Köşk mahallesi, Selimiye mahallesi, Ağaçlıhöyük mahallesi, } \\
\text { Çomakdağ kızılağaç, Çomakdağ ikiztaş, Milas merkez, Şenköy } \\
\text { mahallesi, Ekindere, Kurudere köyü, Çandır köyü, Bafa mahallesi }\end{array}$ \\
\hline Anket çalışmasının yapıldı̆̆ı üretim merkezleri & \\
\hline
\end{tabular}


zeytinin hemen hemen tamamına yakını memecik çeşididir. Elde edilen zeytinyağı kalitesi yüksektir ve Aralık 2020'de Milas Zeytinyağı AB'de coğrafi işaret alarak tescillenmiştir. $\mathrm{Bu}$ durum Milas zeytinyağı üretiminin daha da gelişmesine katkı sağlayacaktır. Ancak gelecekte, ortaya çıkan karasu miktarının da artacağı kuvvetle muhtemeldir. Bu nedenle bölgede karasu sorunun yönetilebilir düzeyde tutulması son derece önem kazanmıştır. Milas'ta 143 mahalle veya köyde toplam 7533 zeytin üreticisi bulunmaktadır. Bu sayı içerisine çok küçük üretim alanları da dahil edilmiştir. Bununla birlikte çalışma, üretiminin yoğun olduğu yerlerde yapılmıştır (Çizelge 1).

Anket çalışmasında hedef kitle, Milas yöresi zeytin üreticileri olduğundan anket uygulamaları sırasından karışıklığa meydan vermemek için katılan üreticilere 'zeytin yetiştiriciliği yapıyor musunuz?' şeklinde soru yöneltilmiş ve bu soruya katılımcıların tamamı evet cevabını vermişlerdir.

\section{Üreticilerin sosyo- ekonomik özellikleri}

Üreticilerin sosyo-ekonomik bazı özelliklerine ilişkin veriler Çizelge 2'de yer almaktadır. Zeytin üreticilerinin sosyo-ekonomik durumlarına bakıldığında; yaş ortalamasının \%45'lik pay ile 60 yaş üstü olduğu görülmüştür. Bu veri, zeytin tarımı ile uğraşanların üst yaş sınırında bulunan kişilerden oluştuğunu, genç nüfusun ilgisinin az olduğunu göstermektedir. Eğitim durumları incelendiğinde, \% 56 ile ilkokul mezunlarının çoğunlukta olduğu fakat \% 22 ile üniversite mezunu kişilerinde zeytincilik ile uğraştığ dikkat çekmektedir. Katılımcıların \%31'inin 100 dekarın üzerinde arazi büyüklüğüne sahip oldukları belirlenmiştir. $\mathrm{Bu}$ nedenle, Milas, zeytin işletme büyüklüğü bakımından oldukça iyi bir durumdadır (Çizelge 2).

\section{Üreticilerin çevresel duyarlılıkları}

Üreticilerin çeresel duyarlılıklarına ilişkin bazı veriler Çizelge 3'te yer almaktadır.

Çizelge 2. Üreticilere ait bazı sosyo-ekonomik frekans değerleri ve oranı

\begin{tabular}{|c|c|c|c|}
\hline & & Frekans & Oran (\%) \\
\hline \multirow[t]{7}{*}{ Yaş aralı̆̆ 1} & $20-29$ & 7 & 6 \\
\hline & $30-39$ & 16 & 14 \\
\hline & $40-49$ & 21 & 18 \\
\hline & $50-59$ & 19 & 17 \\
\hline & 60 üstü & 52 & 45 \\
\hline & Toplam & 115 & 100 \\
\hline & & Frekans & Oran (\%) \\
\hline \multirow[t]{5}{*}{ Eğitim durumu } & İlkokul & 64 & 56 \\
\hline & Ortaokul & 12 & 10 \\
\hline & Lise & 14 & 12 \\
\hline & Üniversite & 25 & 22 \\
\hline & Toplam & 115 & 100 \\
\hline \multirow[t]{7}{*}{ İşletme büyüklükleri } & Dekar & Frekans & Oran (\%) \\
\hline & $0-10$ & 22 & 19 \\
\hline & $10-30$ & 28 & 24 \\
\hline & $30-50$ & 15 & 13 \\
\hline & $50-100$ & 15 & 13 \\
\hline & 100 üstü & 35 & 31 \\
\hline & Toplam & 115 & 100 \\
\hline
\end{tabular}


Çizelge 3. Üreticilerin çevresel duyarlılık durumları (\%)

\begin{tabular}{|l|c|c|c|c|c|c|}
\hline & 1 & 2 & 3 & 4 & 5 & Ortalama \\
\hline $\begin{array}{l}\text { Çevre kirlilĭ̆i, çevre kirliliğinin doğaya ve insan sağlı̆̆ına zararları hakkında bilgi } \\
\text { sahibiyim. }\end{array}$ & 0 & 13 & 39 & 32 & 16 & 3.50 \\
\hline $\begin{array}{l}\text { Çevre kirliliği konusunda eğitim yapan, bu konuda mücadele veren kurum ve } \\
\text { kuruluşların varlığı hakkında bilgi sahibiyim. }\end{array}$ & 25 & 48 & 23 & 4 & 0 & 2.10 \\
\hline Çevre kirliliği son 10 yıl içinde artmıştır. & 0 & 2 & 13 & 60 & 25 & 4.08 \\
\hline Hayvan neslinin ve doğanın tükenmesinde insan faaliyetleri etkilidir. & 0 & 4 & 22 & 52 & 22 & 3.91 \\
\hline $\begin{array}{l}\text { Çevre kirliliğinin artışında tarımsal faaliyetlerin ne derece ve nasıl rol oynadığı } \\
\text { konusunda bilgi sahibiyim. }\end{array}$ & 6 & 17 & 48 & 25 & 4 & 2.94 \\
\hline \multicolumn{1}{|c|}{ Genel ortalama } & & & & & 3.31 \\
\hline
\end{tabular}

1: Hiç katılmıyorum, 2: Az katılıyorum, 3: Orta düzey katılıyorum, 4: Oldukça katılıyorum, 5: Çok fazla katılıyorum Ortalama= Hiç katılmıyorum ile Çok fazla katılıyorum arasında değişen ölçeğin (1, 2, 3, 4 ve 5) frekanslara göre belirlenen ağırlıklı ortalamasıdır.

Çevre kirliliği, çevre kirliliğinin doğaya ve insan sağlığına zararları hakkında ankete cevap veren kişilerin genel olarak orta düzey ile oldukça arasında değişen sınırda (3.50) bilgi sahibi oldukları görülmektedir. Çevre kirliliği konusunda mücadele veren kurumların varlığından ise az haberdar oldukları belirlenmiştir (2.10). Ayrıca "bildiğiniz çevreci kuruluşlara örnek verebilir misiniz?” diye sorulduğunda çoğunluğun Çevre ve Şehircilik Bakanlığı yanıtını verdiği görülmektedir. Ayrıca Tema ve Belediyelerde üreticinin çevre kirliliği kapsamında sorumlu olduğunu düşündüğü kurum ve kuruluşlardır. Çevre kirliliğinin son 10 yıl içinde oldukça arttığını (4.08) ifade etmişlerdir. Bu durum, kişilerin zaman içinde çevre kirliliğindeki artıştan rahatsızlık duyduklarını ve çevresel sorunlara karşı farkındalıklarının bulunduğunu göstermektedir. Çevre kirliliğinin oluşmasında ve hayvan neslinin tükenmesinde insan faaliyetlerinin etkili olduğu görüşüne oldukça katıldıkları (3.91) belirlenmiştir (Çizelge $3)$.

Üreticilerin çeresel duyarlılıklarının genel ortalamasının, orta düzeyin üzerinde (3.31) olduğu tespit edilmiştir. Zeytinyağ1 işletmelerinin zeytin karasuyu sorununa yaklaşımı ile ilgili yapılan çalışmada, Aydın ilinde zeytinyağı işletmelerinin çevre duyarlılıkları 3,52 olarak hesaplanmış olup orta derecede bulunmuştur. İşletmecilerin karasu ile ilgili çevresel tutumları ise 3,14 olarak belirlenmiştir (Yıldırım ve Tunalığlu, 2016). Çalışmamızda bölge üreticilerinin çevre duyarlılıklarının daha yüksek düzeyde (3.31) olduğu görülmektedir. Ancak bunun zetinyağı işletmecilerine yansıdığı pek söylenemez. Sonuçta üretici taşıma maliyetleri nedeniyle en yakın işlemeyi tercih etmekte, işletmenin çevre duyarlılığını önceleyememektedir.

\section{Üreticilerin karasuyun çevresel etkileri konusunda gö- rüş ve farkındalıkları}

Üreticilerin karasuyun çeresel etkileri konusunda görüş ve farkındalıklarına ilişkin bazı veriler Çizelge 4'te yer almaktadir.

Bulundukları bölgede zeytin hasat sezonunda zeytinyağı fabrikalarının atıklarından dolayı bir kirlilik oluştuğu düşüncesine üreticilerin orta düzeyde (2.88) katıldıkları belirlenmiştir. $\mathrm{Bu}$ durum, bölgedeki zeytinyağı fabrikalarından kaynaklı bir kirliliğin varlığına kısmen işaret etmektedir.

Zeytin karasuyunun yapısı ve doğaya zararları konusunda az ve orta düzey arasında değişen (2.56) bilgiye sahip oldukları görülmektedir. Son 10-15 yıl içerisinde zeytin karasuyu nedeniyle oluşan kirliliğin arttığı görüşüne orta düzeyde (2.70) katıldıkları belirlenmiştir. Fakat \% 36 ile az ve \% 18 oranla hiç artmadığını düşünenlerde vardır. Bu kişiler son yıllarda yapılan yasal düzenlemeler ile sorunun iyileştirildi- 
Çizelge 4. Üreticilerin karasuyun çevresel etkileri konusunda görüş ve duyarlılık durumları (\%)

\begin{tabular}{|c|c|c|c|c|c|c|}
\hline & 1 & 2 & 3 & 4 & 5 & Ortalama \\
\hline $\begin{array}{l}\text { Bulunduğunuz yörede zeytin hasat sezonunda zeytinyağı fabrikalarının atıklarından } \\
\text { dolayı çevre kirliliği oluşmaktadır. }\end{array}$ & 9 & 30 & 33 & 23 & 5 & 2.88 \\
\hline Zeytin karasuyunun yapısı ve doğaya zararları konusunda bilgi sahibiyim. & 14 & 39 & 26 & 19 & 2 & 2.56 \\
\hline Zeytin karasuyu nedeniyle yaşanan kirlilik son 10-15 yılda artmıştır. & 16 & 31 & 27 & 19 & 7 & 2.70 \\
\hline Zeytin karasuyu doğaya zarar vermektedir. & 7 & 17 & 42 & 30 & 4 & 3.10 \\
\hline Zeytin karasuyu ile ilgili yasal düzenlemeler konusunda bilgi sahibiyim. & 41 & 32 & 16 & 11 & 0 & 1.97 \\
\hline Zeytin karasuyu ile ilgili yasal düzenlemeler yeterlidir. & 42 & 50 & 7 & 1 & 0 & 1.60 \\
\hline Genel ortalama & & & & & & 2.47 \\
\hline
\end{tabular}

1: Hiç katılmıyorum, 2: Az katılıyorum, 3: Orta düzey katılıyorum, 4: Oldukça katılıyorum, 5: Çok fazla katılıyorum Ortalama= Hiç katılmıyorum ile Çok fazla katılıyorum arasında değişen ölçeğin (1, 2, 3, 4 ve 5) frekanslara göre belirlenen ağırlıklı ortalamasıdır.

ğini belirtmektedir. Karasuyun doğaya orta düzeyde (3.10) zarar verdiğini düşünmektedirler. Zeytin karasuyu ile ilgili yasal düzenlemelerden katılımciların az düzeyde (1.97) haberdar oldukları görülmüştür. Katılımcılar, zeytin karasuyu ile ilgili düzenlemelerin hiç yeterli değil ile az yeterli arasında değişen düzeyde (1.60) olduğunu düşünmektedirler. Bu durumun, zeytin karasuyu ile ilgili yasal düzenlemelerden katılımcıların yeterli düzeyde haberdar olmamasından kaynaklandığı düşünülmektedir (Çizelge 4).

Çevre ve Şehircilik Bakanlığı' nın 'Zeytinyağı Tesislerinde Oluşan Atıksuların Yönetiminde Uyulması Gereken Teknik Hususlar' 2015/10 genelgesine göre zeytin karasuyunun yönetimi ile ilgili olarak iki alternatif plan üzerinde durulmaktadır. Bunlardan birincisi, sürekli (kontinü) santrifüj yöntemiyle zeytinyağı üreten işletmelerin iki fazlı dekantasyon sistemine geçişi, ikinci ise üç fazlı dekantasyon sistemiyle devam edecek işletmelerde oluşacak zeytin karasuyunun sızdırmaz lagünlerde biriktirilerek buharlaştırılmasıdır.

Üreticilerin karasuyun çeresel etkileri konusunda görüş ve farkındalıklarının genel ortalamasının, orta düzeye yakın (2.47) olduğu belirlenmiştir. Bu sonuç bölgede karasuyun çevresel etkileri konusunda yeterli düzeyde bir farkında- lık bulunmadığını göstermektedir. Bu durum bir bakıma olumlu bir sonuçtur. Nihayetinde bölgede karasu ile ilgili bir çevre sorunu bulunmakla birlikte yönetilebilir düzeyde olduğunu göstermektedir.

\section{Üreticilerin karasuyun bertarafı konusunda görüş ve farkındalıkları}

Katılımcılara zeytinyağı işletmelerinin zeytin karasuyu sorununa yönelik çözümlerine ilgi duyup duymadıkları sorulmuştur. Üreticilerin bu konuyu az düzeyde (2.20) merak ettikleri belirlenmiştir. $\mathrm{Bu}$ durum üreticilerin karasuyun bertarafı konusunda farkındalıklarının az olduğunu, pek irdelemediklerini göstermektedir. Karasuyun arıtılabildiği konusunda, düşük düzeyde (1.77) bilgi sahibi olduklarını belirtmişlerdir. Yan ürünler elde edilebildiği, geri dönüşümün olduğunu $\%$ 85'i hiç bilmemekte, $\% 17$ 'si az, \% 11'i ise orta düzeyde bilmektedir (1.37). Karasuyun tarımsal alanlarda kullanımı hakkında hiç ile az düzey arasında değişen bir bilgiye sahip oldukları görülmüştür (1.50). Bölgesel düzeyde tarımsal üretimde karasuyun hemen hemen hiç kullanılmadığı ve bu nedenle bölgede bu konuda çalışmalara ihtiyaç bulunduğu görülmektedir. Karasuyun belirli şartlarda toprağa uygulanabileceği ve diğer bitkisel atıklar ile kompostlanarak organik gübre 
olarak kullanılabileceği konusunda bilgi sahibi olmadıkları belirlenmiştir (1.19). Kompostlama yöntemi ile sorunun çözülebileceği görüşüne orta düzeyde katıldıkları (2.67) belirlenmiştir. Genel olarak bu çözüm yöntemine üreticilerin olumlu baktıkları görülmektedir. Üreticiler ile diyaloğ sırasında kompostlama konusunda genel bilgileri içerecek açıklamalarda bulunulmuştur. $\mathrm{Bu}$ açılamalardan sonra karasuyunun kompostlanması ve toprağa uygulanması iyi bir uygulama olabilir görüşüne orta düzeyde (3.18) katıldıkları saptanmıştır. Böyle bir kompostun kendi topraklarına uygulanmasına da benzer düzeyde (2.94) katıldıkları belirlenmiştir. Üreticiler karasuyun kompostlanması ve toprağa uygulanmasını genel olarak olumlu karşılamışlardır (Çizelge 5).

Üreticilerin karasuyun bertarafı konusunda görüş ve farkındalıklarına ilişkin bazı veriler Çizelge $5^{\text {'te yer }}$ almaktadır.

Üreticilerin karasuyun bertarafı konusunda görüş ve farkındalıkları genel ortalaması, az düzeye yakın (2.10) bulunmuştur. Zeytinyağı işletmelerinin zeytin karasuyu sorununa yaklaşımı ile ilgili Aydın ilinde yapılan çalışmada, karasuyun bertarafı konusunda işletmecilerin tercihleri arasında; hem sulama suyu hem de gübre olarak kullanım, çevreye (alıcı ortama) doğrudan deşarj ve bölgesel biriktirme seçenekleri ilk üç sırada yer almıştır (Yıldırım ve Tunalıoğlu, 2016). Çalışmamızda da katılımcılar tarafından benzer önerilerde bulunulmuş, ancak kompost materyali olarak toprağa uygulanmasının da olumlu karşılanacağı ortaya çıkmıştır. Bilimsel çalışmalar kompostlaştırma yaklaşımını destekler niteliktedir. Zira İki faz ve üç faz üretim

Çizelge 5. Üreticilerin karasuyun bertarafı konusunda görüş ve farkındalık durumları (\%)

\begin{tabular}{|c|c|c|c|c|c|c|}
\hline & 1 & 2 & 3 & 4 & 5 & Ortalama \\
\hline $\begin{array}{l}\text { Zeytinyağı fabrikalarının zeytin karasuyu sorununa yönelik çözümleri konusuna } \\
\text { ilgi duyarım. }\end{array}$ & 24 & 43 & 20 & 13 & 0 & 2.20 \\
\hline Zeytin karasuyunun arıtılabildiği konusunda bilgi sahibiyim. & 47 & 31 & 20 & 2 & 0 & 1.77 \\
\hline $\begin{array}{l}\text { Zeytin karasuyundan yan ürünler elde edildiğini ve geri dönüşümünün olduğu } \\
\text { konusunda bilgi sahibiyim. }\end{array}$ & 74 & 15 & 11 & 0 & 0 & 1.37 \\
\hline Zeytin karasuyunun tarımsal alanlarda kullanımı konusunda bilgi sahibiyim. & 63 & 25 & 12 & 0 & 0 & 1.50 \\
\hline $\begin{array}{l}\text { Zeytin karasuyunun belirli şartlarda toprağa uygulanabilirliği ve diğer bitkisel } \\
\text { artıklar ile kompostlanarak organik gübre olarak kullanılabileceği konusunda bilgi } \\
\text { sahibiyim. }\end{array}$ & 82 & 12 & 6 & 0 & 0 & 1.19 \\
\hline Karasu sorunu kompostlama yöntemi ile çözülebilir. & 13 & 28 & 38 & 21 & 0 & 2.67 \\
\hline Karasuyun komposlanması ve toprağa uygulanması iyi bir uygulama olabilir. & 7 & 16 & 33 & 38 & 6 & 3.18 \\
\hline $\begin{array}{l}\text { Zeytin karasuyu kullanılarak hazırlanmış kompostun kendi bahçe toprağıma } \\
\text { uygulanmasını isterim. }\end{array}$ & 2 & 23 & 38 & 37 & 0 & 2.94 \\
\hline Genel ortalama & & & & & & 2.10 \\
\hline
\end{tabular}

1: Hiç katılmıyorum, 2: Az katılıyorum, 3: Orta düzey katılıyorum, 4: Oldukça katılıyorum, 5: Çok fazla katılıyorum. Ortalama = Hiç katılmıyorum ile Çok fazla katılıyorum arasında değişen ölçeğin (1, 2, 3, 4 ve 5) frekanslara göre belirlenen ağırlıklı ortalamasıdır. 
sisteminde ortaya çıkan karasu ile hazırlanan komposttun organik domates fidesi üretiminde kullanılabileceği belirlenmiştir (Tüzel vd., 2020). İlave olarak, toprak verimliliğine olumlu etkileri olabileceği belirtilmektedir (Gomez-Munoz vd., 2019). Çalı̧smamızda üreticilerin karasu kompostuna olumlu yaklaşımı, gelecekte, üretimde kompost kullanımının yaygınlaşmasına katkı sağlayacaktır.

Üreticilerin genel olarak çevre sorunlarından orta düzeyde haberdar oldukları anlaşılmaktadır. Bununla birlikte zeytin karasuyunun çevresel etkileri konusunda kararsız kaldıkları tespitedilmiştir. Karasuyun oluşturduğugörüntüvekokudan çoğunluk rahatsız olmaktadır. Karasu geçtiği yeri kurutur şeklindeki tabirleri dikkat çekmektedir. Buna karşın şaşırtıcı olarak çokta rahatsızlık duymadıkları, çevresel anlamda fazla zararlı olmadığı düşüncesi ağırlıktadır. Karasuyun fitotoksik etkisinden ve kirlilik yükünün fazlalığından yeterince bilgi sahibi olmadıkları belirlenmiştir. Karasuyun toprağa uygulanmasının üreticiler tarafından yeterince bilinen bir uygulama olmadığı anlaşılmaktadır. Bununla birlikte üreticilerin yeniliklere açı, çözüm odaklı oldukları görülmüştür. Üreticilere konu kapsamında yapılacak bilgilendirmeler ve arazi çalışmalarının olumlu getirisinin olacağı düşünülmektedir.

\section{SONUÇ}

Zeytin karasuyu, karasal ve denizel ekosisteme zarar verebilecek bir potansiyele sahiptir. Bununla birlikte içerdiği yüksek oranda organik madde ve N, P, K başta olmak üzere birçok besin elementleri nedeniyle kompostlama gibi işlemlere tabi tutularak tarımda kullanılabilecek bir materyal olabileceği konusunda çok sayıda bilimsel çalışma yer almaktadır. Bazı çalışmalar karasuyun toprağın fiziksel, kimyasal ve mikrobiyolojik özelliklerine olumlu etkilerinin olduğunu göstermektedir.

Zeytin karasuyu sorununun çözümü için farklı yöntemler geliştirilmiştir. Bunlar arasında; entegre tesisler kurulması, üç fazlı işletmelerin iki fazlı sisteme dönüştürülmesi, lagünlerin kullanılması, arıtma sistemlerinin kurulması ve kompostlama bulunmaktadır. Ülkemizde, bertaraf için, aktif olarak uygulanan yöntem lagünlerde buharlaştırmadır ve yasalar ile desteklenmektedir. Zeytinyağı tesislerinde oluşan atıkların ayrı ayrı ele alınması yerine tümünün bir arada entegre bir yönetim sisteminde bertarafı tartışılmalıdır.

Karasuyun tarımda kullanılması konusunda kapsamlı çalışmalara ihtiyaç duyulmaktadır. Milas İlçesi zeytin üreticilerine yönelik yapılan anket çalışmasında, karasu sorunu konusunda farkındalık bulunduğu ve tarımda kullanılmasına genellikle olumlu bakıldığı, ancak yine de bazı tereddütlerin var olduğu tespit edilmiştir. Bu çerçevede tereddütlerin giderilmesi için çalışmaların bir bölümünün, üretici bazında karasuyun kompostlanarak toprağa uygulandığı demostrasyon çalışmaları şeklinde yürütülmesi gerektiği düşünülmektedir. Olumlu sonuçları görüldükçe, tarım topraklarına uygulanması yaygin hale gelecek ve zararlı bir atık olan karasu bir çevre sorunu olmaktan çıkıp, aksine bitkisel üretimde verim artışı sağlayan bir materyal haline dönüşecektir. $\mathrm{Bu}$ nedenle üreticiler, karasuyun tarımda kullanılmasına yönelik alternatif uygulamalarda bulunabilecek, sorunun çözümüne katkı sağlayabilecek paydaşlar olarak görülmektedir.

\section{Yazarların makalede katkı oranları beyanı;}

Yazarlar makaleye, aşağıda belirtilen oranlarda katkı sağlamış olduklarını beyan ederler.

\begin{tabular}{|l|l|l|}
\hline $\begin{array}{l}\text { Yazar ad1, } \\
\text { soyadı }\end{array}$ & $\begin{array}{l}\text { Katk1 } \\
\text { oranı } \\
(\%)\end{array}$ & Yapılan katkı \\
\hline P. M. & 40 & $\begin{array}{l}\text { Kaynak araştırma, veri } \\
\text { toplama, işleme, yazım }\end{array}$ \\
\hline M. G. & 30 & $\begin{array}{l}\text { Değerlendirme, analiz, } \\
\text { eleştirel inceleme, yazım }\end{array}$ \\
\hline İ. Y. & 30 & Fikir, yöntem, düzeltme \\
\hline Çıar & \multicolumn{2}{|c|}{ çatışması beyanı; }
\end{tabular}

Çalışma kapsamında yazarlar, aralarında herhangi bir kişisel ve finansal çıkar çatışması olmadığını beyan ederler.

\section{Araştırma ve yayın etiğine uygunluk beyanı;}

$\mathrm{Bu}$ makalede sorumlu yazar, Araştırma ve Yayın Etiğine uyulduğunu beyan eder. 


\section{KAYNAKLAR}

Alfano, G., Belli, C., Lustrato, G., Ranalli, G. (2008) Pile Composting of Two-phase Centrifuged Olive Husk Residues: Technical Solutions and Quality of Cured Compost. Bioresource Technology, 99: 4694-4701.

Altındal, D., Altındal N. (2018). Allelopathic Effects of Olive Mill Wastewater (OMW) on Sainfoin (Onobrychis viciifolia Scop.) Germination. International Journal of Agriculture, Forestry and Life Science, 2 (2): 87-92.

Altieri, R., Esposito, A. (2010) Evaluation of the Fertilizing Effect of Olive Mill Waste Compost in Short-term Crops. International Biodeterioration and Biodegradation, 64: 124-128.

Azbar, N., Bayram, A., Filibeli, A., Muezzinoglu, A., Sengul F., and Ozer, A. (2004) A review of waste management options in olive oil production. Crit. Rev. Environ. Sci. Technol. 34: 209-247.

Ben Sassi A., Boularbah A., Jaouad G., Walker ve Boussaid A. (2006) A Comparison of Olive Oil Mill Wastewaters from Three Different Processes in Morocco. Bioproces Biochem, 41: 74-78.

Bektaş, F. ve Şirin, E.F. (2018) Yeni Çevresel Paradigma Ölçeği ile Dağclların Çevreye Yönelik Tutumlarının Değerlendirilmesi. Türk Spor Bilimleri Dergisi, 1(1): 20-26.

Buchmann, C., Felten, A., Peikert, B., Muñoz, K., Bandow, N., Dag, A., Schaumann, G.E. (2015) Development of Phytotoxicity and Composition of a Soil Treated with Olive Mill Wastewater (OMW): An incubation study. Plant and Soil, 386(1): 99-112.

Cayuela, M.L., Sanchez-Monedero, M.A., Roig, A. (2010) Two-phase Olive Mill Waste Composting: Enhancement of the Composting Rate and Compost Quality by Grape Stalks Addition. Biodegradation, 21: 465-473.

Chaari, L., Ellouni, N., Mseddi, S., Gargouri, K., Rouina, B.B., Mechchichi, T., Kallel, M. (2015) Changes in Soil Macronutrients after a LongTerm Application of Olive Mill Wastewater. Journal of Agricultural Chemistry and Environment, 4:1-13.
Dakhli , R., Khatteli, H., Ridha, L., Taamallah, H. (2018) Agronomic Application of Olive Mill Waste Water: Short-Term Effect on Soil Chemical Properties and Barley Performance Under Semiarid Mediterranean Conditions. Enviromental Quality, 27:1-17.

Di Bene C, Pellegrino E, Debolini M, Silvestri N, Bonari E. (2013) Short-and Long-Term Effects of Olive Mill Wastewater Land Spreading on Soil Chemical and Biological Properties. Soil Biology and Biochemistry, 56: 21-30.

Garcia-Gomez, A., Roig, A., Bernal, M.P. (2003) Composting of the Solid Fraction of Olive Mill Wastewater with OL: Organic Matter Degradation and Biological Activity. Bioresource Technology, 86: 59-64.

Gomez-Munoz, B., Hatch, J.D., Bol, R., Garcia-Ruiz, R. (2019) The Compost of Olive Mill Pomace: From a Waste to a Resource- Environmental Benefits of Its Application in Olive Oil Groves. http://dx.doi.org/10.5772/48244. (Erişim:11.07.2019).

Hachicha, S., Cegarra, J., Sellami F., Hachicha, R., Drira, N., Medhioub, K., Ammar, E. (2009) Elimination of Polyphenols Toxicity From Olive Mill Wastewater Sludge by its Co-Composting with Sesame Bark, Journal of Hazardous Materials, 161: 1131-1139.

Murat Hocaoğlu, S., Gürsoy Haksevenler, B. H., Baştürk, İ., Ergenekon, Ş. (2019) Zeytinyağı Tesislerinde Oluşan Karasuyun Bertaraf Alternatiflerinin Maliyet Açısından Karşılaştırılması. BAUN Fen Bil. Enst. Dergisi, 21(2): 623-637.

Murat Hocaoglu, S., Gursoy Haksevenler, B. H., Basturk, İ., Talazan, P., Aydoner C., (2018) Assessment of Technology Modification for Olive Oil Sector Through Mass Balance: A Case Study for Turkey. Journal of Cleaner Production, 188:786795.

İlay, R., Erarslan, G., Kavdır, Y. (2019) Pirina ve Balık Atıklarının Birlikte Kopmpostlanması ve Toprak Islahında Kullanılması. Anadolu Tarım Bilimleri Dergisi, 34:201-2019.

Kapellakis I, Tzanakakis, VA, Angelakis AN. (2015) Land Application-Based Olive Mill Wastewater 
Management. Water, 7(2): 362-376.

Karademir, F.K. (2016) Zeytin ve Zeytinyağı. Efil yayınevi. (Editör: İ.Yokaş) Bölüm 4. s.122-157.

Killi D. (2008) Zeytin Katı Atığı Pirinanın Toprak Kalitesi Üzerine Etkileri ve Tarım Toprak Düzenleyici Olarak Kullanım Olanakları. ÇOMÜ Fen Bilimleri Enstitüsü Yüksek Lisans Tezi s. 94.

Komilis, D.P., Tziouvaras, I.S., (2009) A Statistical Analysis to Assess the Maturity and Stability of Six Composts. Waste Management, 29: 15041513.

Manios, T., Manjadakis, K., Kalogeraki, M., Mari, E., Stratakis, E., Terzakis, S., Boytzakis, P., Naziridis, Y., Zampetakis, L. (2006) Efforts to Explain and Control the Prolonged Thermophilic Period in Two-phase Olive Oil Mill Sludge Composting. Biodegradation, 17: 285-292.

Moraetis, D., Stamati, F.E., Nikolaidis, N.P., Kalogerakis, N. (2011) Olive Mill Wastewater Irrigation of Maize: Impacts on Soil and Groundwater. Agricultural Water Management, 98(7): 11251132.

Okur, N., Kayıkçığlu, H.H., Okur, B., Yağmur, B., Sponza Teresa, D., Kara, R. S. (2019) A Study of Olive Mill Wastewaters Obtained from Different Treatment Processes Effects on Chemical and Microbial Properties of a Typic Xerofluvent Soil and Wheat Yield. file:///C:/Users/HP/Downloads/TAR-1902-75_manuscript_1\%20(5).pdf (Erişim:18.10.2019).

Paredes, C., Bernal, M.P., Cegarra, J., Roig, A. (2002) Bio-degradation of Olive Mill Wastewater Sludge by its Co-composting with Agricultural Wastes. Bioresource Technology, 85: 1-8.

Principi, P., Ranalli, G., Da Borso, F., Pin, M., Zanardini, E., Sorlini, C. (2003) Microbiological Aspects of Humid Husks Composting. Part B Pesticides, Food Contaminant, and Agricultural Wastes. Journal of Environmental Science and Health, 38: 645-661.

Sánchez-Arias, V., Fernández, F.J., Villaseñor, J., Rodríguez, L. (2008) Enhancing the Co-composting of Olive Mill Wastes and Sewage Sludge by the Addition of an Industrial Waste. Bioresource Technology, 99: 6346-6353.
Sellami, F., Jarboui, R., Hachicha, S., Medhioub, K., Ammar, E. (2008) Co-composting of Oil Exhausted Olive-cake, Poultry Manure and Industrial Residues of Agro-food Activity for Soil Amendment. Bioresource Technology, 99: 11771188.

TÜİK, (2019) Türkiye İstatistik Kurumu. Bitkisel Üretim İstatistikleri. https://biruni.tuik.gov.tr (Erişim:10.01.2021).

Tunalığlu, R., Bektaş, T. (2010) Türkiye Zeytinciliğinde Karasu Sorunu. Zeytin Bilimi Dergisi, 1 (2) : 6571.

Tunç, S.M., Ünlü, A. (2015) Zeytinyağı Üretim Atıksularının Özellikleri Çevresel Etkileri ve Arıtım Teknolojileri, Nevşehir Bilim ve Teknolojı Dergisi, 4: 44-74.

Tüzel, Y., Ekinci, K., Öztekin, G. B., Erdal, İ., Varol, N., Merken, Ö. (2020). Utilization of Olive Oil Processing Waste Composts in Organic Tomato Seedling Production. Agronomy, 10, 797; doi:10.3390/agromomy10060797.

Uzun, N., Seferoğlu, S. (2017) Zeytin Karasu Keki Uygulamasının Toprağın Bazı Özelliklerine Etkisi. ADÜ Ziraat Dergisi, 14:33-38.

Yıldırım, R., Tunalıoğlu, R. (2016) Aydın'da Karasu Sorunu ve Zeytinyağı İşletmelerinin Çözüme Yönelik Tercihlerinin İncelenmesi. Adnan Menderes Üniversitesi Ziraat Fakültesi Dergisi, 13(2) : 39 - 48. 